\title{
PENGARUH KOMPETENSI PROFESIONAL TERHADAP MOTIVASI KERJA GURU HONORER TK SE KECAMATAN KENDARI BARAT KOTA KENDARI
}

\author{
Halmuniati $^{1}$ dan Siti Sabania ${ }^{2}$ \\ ${ }^{1}$ Fakultas Tarbiyah dan Ilmu Keguruan IAIN Kendari \\ Email:halmuniati88@gmail.com \\ ${ }^{2}$ Fakultas Tarbiyah dan Ilmu Keguruan IAIN Kendari \\ Email: sitisabania1986@gmail.com
}

\begin{abstract}
Abstrak
Penelitian ini bertujuan untuk menguji dan menjelaskan pengaruh kompetensi professional terhadap motivasi kerjaguru honorer TK se Kecamatan Kendari Barat Kota Kendari Provinsi Sulawesi Tenggara tahun 2018. Penelitian ini menggunakan pendekatan kuantitatif dengan metode pengumpulan data menggunakan angket (Kuesioner).Populasi dalam penelitian ini adalah guru honorer yang ada di Kecamatan Kendari Barat Kota Kendari sebanyak 30 orang guru.Teknik penarikan sampel menggunakan sampling jenuh dimana semua populasi digunakan sebagai sampel yang terdiri dari 30 orang guru honorer.Teknik analisis data untuk menjawab permasalahan pada hipotesis penelitian ini adalah analis SEM berbasis Partial Least Square (PLS).hasil analisis data menunjukkan bahwa nilai koefisien jalur kompetensi profesional terhadap motivasi kerja sebesar 0,571 dengan nilai $t_{\text {hit }}$ sebesar 4,232 artinya $t_{h i t}>t_{t a b} 1,96$. Semua indikator pada variabel kompetensi profesional dan variabel motivasi kerja memiliki nilai $t_{\text {hit }}$ lebih besar dari nilai $t_{t a b} 1,96$. Dengan Hasil ini menunjukkan bahwa kompetensi profesional memiliki pengaruh terhadap motivasi kerja.
\end{abstract}

Kata kunci : Kompetensi Profesional, Motivasi Kerja, PLS 


\title{
THE INFLUENCE OF COMPETENCE PROFESSIONAL TEACHER TO WORK MOTIVATION OF HONORARY TEACHER KINDERGARTEN IN THE SUB-DISTRICT OF WEST KENDARI CITY
}

\author{
Halmuniati $^{1}$ dan Siti Sabania ${ }^{2}$ \\ ${ }^{1}$ Fakultas Tarbiyah dan Ilmu Keguruan IAIN Kendari \\ Email:halmuniati88@gmail.com \\ ${ }^{2}$ Fakultas Tarbiyah dan Ilmu Keguruan IAIN Kendari \\ Email: sitisabania1986@gmail.com
}

\begin{abstract}
This study aimed explained and examine the influence of competence professional teacher to work motivation of honorary teacher kindergarten in the Sub-District of West Kendari City of Southeast Sulawesi Province in 2018. This study used a quantitative approach with data collection method used questionnaire. The population in this research was all honorary teacher which exists in the sub-district west Kendari city of Kendari for 30 people. Technique of taking sample done saturated sampling where all populations are used as a sample consisting of 30 honorary teachers. Technique of data analysis to answer the problem in hypothesis this research was Partial Least Square (PLS). The results of data analysis show the path coefficient of professional competence on work motivation is 0,571 with a value $t_{h i t}$ of 4.232. meaning $t_{h i t}>t_{t a b} 1$ 1,96. All indicators on professional competence variables and work motivation variables have values $t_{h i t}>t_{t a b}$. Result of the research shows that competence professional teachers have had a positive and significant effect to work motivation
\end{abstract}

Keywords : Competence Professional Teachers, Work Motivation, PLS. 


\section{Pendahuluan}

Pendidikan bukan hanya sekedar proses yang bertujuan untuk membentuk manusia yang cerdas dan terampil dalam melaksanakan pekerjaannya. Tinggi rendahnya mutu pendidikan sangat ditentukan oleh sistem pendidikan yang diberlakukan dalam membangun pendidikan. Terkait dengan hasil pendidikan yang belum memadai, maka banyak upaya yang dilakukan oleh pemerintah telah mengupayakan untuk mengatasi terkait rendahnya hasil pendidikan yang dapat dilihat dari rendahnya hasil belajar siswa.

Salah satu faktor yang berpengaruh terhadap kualitas pendidikan Indonesiaadalah guru.Masyarakat menempatkan guru pada suatu tempat yang lebih terhormat didalam lingkungannya. Karena dari seorang guru masyarakat diharapkan agar dapat memperoleh ilmu pengetahuan, terlebih bagi kelangsungan hidup bangsa ditengah-tengah lintasan kemajuan perkembangan teknologi yang makin canggih dengan segala perubahan serta pergeseran nilai yang cenderung memberikan nuansa kepada kehidupan yang menuntut ilmu dan seni dalam kadar dinamik untuk mengadaptasikan diri.

Terkait dengan tidak efektifnya tunjangan profesional guru, Menteri Pendidikan Nasional menyebutkan bahwa guru hanya aktif menjelang sertifikasi tetapi setelah dinyatakan lolos, kualitas mereka justru semakin menurun.sehingga muncul persoalan yang kemudian muncul yang mengansumsikan bahwa guru telah memiliki kompetensi itu sebab mereka telah disertifikasi, akan tetapi tampaknya dalam jangka panjang sulit untuk dapat dipertanggungjawabkan secara akademik. Karena sertifikasi itu sangat erat kaitannya dengan proses belajar, maka perolehan sertifikasi itu tidak dapat diasumsikan cerminan dari kompetensi yang unggul selama menjadi seorang guru. Seharusnya setelah guru memperoleh sertifikasi sudag sepantasnya menjadikannya sebagai motivasi merupakan bagi guru agar dapat selalu meningkatkan kompetensi dengan cara belajar sepanjang hayat. ${ }^{1}$

\footnotetext{
${ }^{1}$ Mohamad Syarif Sumantri \& Prayuningtyas Angger Whardani. 2017. Relationship between Motivation to Achieve and Professional Competence in the Performance of Elementary School Teachers. International Education Studies; Vol. 10, No. 7; 2017 ISSN 1913-9020 E-ISSN 1913-9039.
} 
Berdasarkan hasil pengamatan yang dilakukan di beberapa sekolah terutama di Taman Kanak-Kanak, ditemukan bahwa tingkat kehadiran guru dalam mengajar di sekolah tidak terlalu optimal.Data menunjukkan bahwa kehadiran guru masih dalam kisaran 90\% dari masing-masing sekolah. Tingkat disiplin guru, kreatifitas dan inovasi masih rendah baik dalam hal program maupun implementasi pada proses belajar mengajar yang efektif. Upaya meningkatkan kinerja guru sangat sulit dilaksanakan.Data diperoleh dari Departemen Pendidikan Kendari 2017 menunjukkan bahwa mereka bekerja secara minimal kondisi kerja yang memuaskan dan bahwa mereka menghadapi masalah mengenai sumber daya manusia. Banyak faktor yang memengaruhi kinerja pekerjaan guru, termasuk gaji guru rendah, gaya kepemimpinan yang tidak pantas, fasilitas yang dilakukan tidak mendukung proses pembelajaran, dan motivasi guru rendah.

Salah satu kompetensi yang wajib dimiliki oleh guru yaitu kompetensi professional.Dimana guru yang memiliki kinerja yang rendah bisa dilihat dari perilaku guru yang bersangkutan. Rendahnya kinerja guru tersebut bisa dilihat dari ketidakdisiplinan dalam melaksanakan tugas, tidak tepat waktu, cara mengajarnya sangat monoton, motivasi yang dimiliki kurang, keinginannya bekerja selalu ingin cepat selesai serta kurangnya dalam memperhatikan kualitas hasil pekerjaan, dan jarang sekali melakukan evaluasi akan kinerjanya. Selain profesionalisme guru dalam melaksanakan proses pendidikan dalam suatu satuan pendidikan, rasa percaya diri yang tergabung dalam sebuah konsep diri akademik guru juga ditafsirkan sangat kuat memberikan pengaruh terhadap kinerja guru dalam melaksanakan pendidikan. Berdasarkan hasil penelitian yang dilakukan oleh Hasniatin Nabila tahun 2016 yang dilakukan pada guru SMP di Kabupaten Trowulan diperoleh bahwa kompetensi profesional sangat berpengaruh terhadap kinerja guru. ${ }^{2}$

Menjadi guru tanpa motivasi kerja akan cepat merasa jenuh karena tidak adanya unsur pendorong. Motivasi mempersoalkan bagaimana caranya gairah kerja guru, agar guru mau bekerja keras dengan menyumbangkan segenap kemampuan, pikiran, keterampilan untuk mewujudkan tujuan pendidikan. Motivasi kerja

${ }^{2}$ Haniatin Nabila. 2016. ISSN: 2528-617X. Yogyakarta. 
merupakan suatu keadaan yang berhubungan dengan psikologis yang dapat mendorong seseorang atau pegawai untuk melaksanakan suatu usaha ata kegiatan dalam mencapai tujuan organisasi maupun tujuan individual. Seperti penelitian yang dilakukan oleh $\mathrm{H}$. Muhammad Arifin tahun 2014 pada guru SMA di Kota Jayapura pada 117 responden dari 346 guru dengan memberikan kuisioner diperoleh bahwa kompetensi profesional dapat mempengaruhi motivasi kerja guru yang ada di SMA jayapura. ${ }^{3}$

\section{Kompetensi Profesional Guru}

Kompetensi yang berkaitan dengan keterampilan yang dimiliki oleh guru dalam proses pembelajaran itu termasuk dalam kategori kompetensi profesional. Kompetensi profesional adalah penguasaan materi dari pembelajaran yang luas serta lebih mendalam yang meliputi penguasaan isi kurikulum dan substansi mata pelajaran ilmiah secara filosofis, kemampuan menangani tugas penyesuaian dan kompetensi dosen sangat penting karena berkaitan langsung dengan kinerja yang ditunjukkan. ${ }^{4}$

Perbedaan antara profesi guru denganprofesi lainnya terletak dalam tugas dan tanggung jawabnya. Tugas dan tanggung jawab tersebut erat kaitannya dengan kemampuan yang disaratkan untuk memangku profesi tersebut. Guru merupakan jabatan atau profesi yang memerlukan keahlian khusus sebagai guru". Oleh karena itu setiap guru pada suatu lembaga pendidikan harus memiliki berbagai ketentuan atau syarat-syarat untuk menjadi sebagai seorang guru. Salah satu syarat tersebut adalah memiliki kompetensi (kemampuan) untuk melaksanakan kegiatan pengajaran dan pendidikan dengan optimal.Syarat lainnya adalah guru harus sehat mental dan fisik, serta memiliki ijazah keguruan yang dikeluarkan oleh lembaga pendidikan keguruan. ${ }^{5}$

${ }^{3}$ H. Muhammad Arifin. 2014. The Influence of Competence, Motivation, and Organisational Culture to High School Teacher Job Satisfaction and Performance. Canadian Center of Science and Education.

${ }^{4}$ Adnan Hakim. 2015. Contribution of Competence Teacher (Pedagogical, Personality, Professional Competence and Social) On the Performance of Learning. The International Journal Of Engineering And Science (IJES) Volume 4 Issue 2 , 3.

${ }^{5}$ Feralys Novauli, M. 2015. Kompetensi Guru dalam Meningkatkan Prestasi Belajar. Jurnal Administrasi Pendidikan Pascasarjana Universitas Syiah Kuala. Vol,3. 
Kompetensi profesional merupakan kemampuan guru dalam menguasai pengetahuan berdasarkan bidang ilmu pengetahuan, teknologi, serta seni dan budaya yang dipegangnya sekurangkurangnya meliputi penguasaan: a) materi pelajaran yang luas dan mendalam sesuai dengan standar isi dari program satuan pendidikan, mata pelajaran, dan/atau kelompok mata pelajaran yang akan diampu dan b) konsep dan metode disiplin keilmuan, teknologi, atau seni yang relevan, yang secara konseptual sesuai dengan program satuan pendidikan, mata pelajaran, dan/atau kelompok mata pelajaran yang akan diampu. ${ }^{6}$

Kompetensi profesional adalah berbagai kemampuan yang diperlukan agar dapat mewujudkan dirinya sebagai sosok yang profesional. Kompetensi profesional guru sangat diperlukan guna mengembangkan kualitas dan aktivitas tenaga kependidikan dalam hal ini guru. Guru merupakan faktor penentu mutu pendidikan dan keberhasilan pendidikan di sekolah. Guru lebih menguasai konsep/teori dalam materi yang akan disampaikan. Penyampaian materi pun akan menggunakan model-model pembelajaran yang inovatif yang dikaitkan dengan kehidupan sehari-hari siswa sehingga akan memberikan dampak yang positif terhadap prestasi belajar. Oleh karena itu, tingkat kompetensi profesional guru disuatu sekolah dapat dijadikan barometer bagi mutu mutu dan keberhasilan pendidikan di sekolah.karakteristik profesionalisme guru bisa ditinjau dari enam komponen, yaitu: 1) Pemahaman dan penerimaan dalam melaksanakan tugas; 2) Kemauan melakukan kerjasama secara efektif dengan peserta didik, guru, orang tua peserta didik, dan masyarakat; 3) Kemampuan mengembangkan visi dan pertumbuhan jabatan secara terus menerus; 4) Mengutamakan pelayanan dalam tugas; 5) Mengarahkan, menekan, dan menumbuhkan pola perilaku peserta didik; 6) Melaksanakan kode etik jabatan. ${ }^{7}$

\footnotetext{
${ }^{6}$ Maulinar. 2015. Kompetensi Guru Dalam Memotivasi Siswa Dalam proses Pembelajaran Pada SMP Negeri 1 Syamtalira Bayu Kabupaten Aceh Utara. Jurnal Administrasi Pendidikan Pascasarjana Unsiyah Vol 3 No 1, 142-157.

${ }^{7}$ Kasmawati.2015. Pengaruh Guru Profesional Terhadap Motivasi Belajar Peserta Didik Pada SMPN 1 Bontoramba Kabupaten Jeneponto.Auladuna, vol. 2 no. 1 juni: $42-64$
} 
Guru profesional adalah orang yang memiliki kemampuan dan keahlian khusus dalam bidang keguruan sehingga ia mampu melakukan tugas dan fungsinya sebagai guru dengan kemampuan maksimal. Guru sebagai pendidik yang profesional memiliki citra yang baik di dalam masyarakat dimana guru sebagai pendidik profesional dikatakan mempunyai citra yang baik dimasyarakat apabila mampu menunjukkan kepada masyarakat bahwa ia layak untuk menjadi panutan serta teladan bagi masyarakat yang ada disekelilingnya. ${ }^{8}$

Berdasarkan pendapat tersebut, dapat disimpulkan bahwa yang dimaksud dengan kompetensi profesional guru adalah kemampuan yang harus dimiliki seorang guru baik pengetahuan, keterampilan maupun nilai dan sikap untuk melakukan suatu pekerjaan yang diperoleh melalui pendidikan profesi dan tidak dapat digantikan oleh orang lain yang tidak memiliki profesi tersebut.

\section{Motivasi Kerja Guru}

Beberapa faktor yang dapat mempengaruhi karyawan agar dapat mencapai prestasi yang lebih tinggi, yaitu:

1. Faktor Ability. Secara psikologis, kemampuan terdiri dari kemampuan potensi (IQ) dan kemampuan reality (knowledge + skill).

2. Faktor Motivasi. Motivasi diartikan suatu sikap (attitude) pimpinan dan karyawan terhadap situasi kerja (situation) dilingkungan organisasi. ${ }^{9}$

Guru yang memiliki motivasi tinggi akan memandang berbagai kekurangan yang ada di sekolah sebagai tantangan. Ia akan berusaha sedapat mungkin untuk mengatasi kekurangan itu. Dengan adanya perhatian yang baik terhadap guru, akan dapat menimbulkan motivasi para guru untuk berbuat yang baik terhadap guru, akan dapat menimbulkan motivasi para guru untuk berbuat

${ }^{8}$ Jafaruddin.2015. Kompetensi Profesional Guru Dalam Meningkatkan Prestasi Belajar Siswa SMAN 1 Kuta Cot Glie Kabupaten Aceh Besar.Intelektualita Volume 1 No. 3, 63

${ }^{9}$ Zamharil Yahya dan Fitri Hidayati. 2017. Analisis Kompetensi Terhadap Penilaian Kinerja Dosen (Studi Kasus Dosen UIN Sultan Syarif Kasim Riau). Jurnal Penelitian sosial keagamaan, Vol.17, No.1 
yang terbaik dalam melakukan tugas sehingga menumbuhkan komitmen dalam melakukan pekerjaan yang berkualitas dan bertanggungjawab demi kemajuan organisasi. Motivasi guru mempengaruhi mereka bekerja secara efisien dan sukarela. ${ }^{10}$ Selain itu Motivasi guru mempengaruhi hampir semua faktor yang terkait dengan guru dalam sistem sekolah. ${ }^{11}$ Motivasi merupakan faktor penting yang yang paling banyak mempengaruhi kinerja guru.

Motivasi kerja wujudnya tidak hanya dalam kepentingan yang ekonomis saja, akan tetapi biasanya juga berbentuk kebutuhan psikis sehingga dapat melakukan pekerjaan menjadi lebih aktif dan efisien. Motivasi juga merupakan dorongan mental yang mampu menggerakkan dan mengarahkan perilaku dari hidup manusia".Motivasi juga bisa menjadi kunci bagi kreativitas kerja.Kreativitas kerja tersebut dapat ditingkatkan dengan motivasi kerja yang tinggi, pengetahuan serta keahlian dalam melakukan tugas dan peran positif yang dimiliki seseorang. ${ }^{12}$

\section{Metode Penelitian}

Jenis pendekatan yang digunakan dalam penelitian ini adalah Pendekatan kuantitatif dengan metode pengumpulan data menggunakan angket (Kuesioner).Metode analisis data yang digunakan dalam penelitian ini yaitu analisis deskriptif dan analisis statistik inferensial yaitu Structural Equation Modeling (SEM) berbasis varians Partial Least Square (PLS) dengan menggunakan Smart PLS, Microsof Excel, dan Sofware SPSS. ${ }^{13}$ Metode pengumpulan data dalam penelitian ini dengan menggunakan Angket, dilakukan dengan menyebar angket kepada 30 orang guru

${ }^{10}$ Ates, H., Yildiz, B., \& Yildiz, H. 2012. Can Herzberg's Two Factor Theory Explain the Motivation Perceptions of Teachers in Public Schools? An Empirical Research, Knowledge Economy and Management Magazine, VII(II), 147162

${ }^{11}$ Tecer, O. 2011. The Effect of Teachers' Internal Motivation Job Satisfaction Levels of School Supervisors Made by Primary Education Inspectors, Unpublished Master's Thesis, Ahi University Social Science Institute, Kirsehir

${ }^{12}$ Titin Eka Ardiana. 2017. Pengaruh Motivasi Kerja Guru Terhadap Kinerja Guru Akuntansi Smk Di Kota Madiun.Jurnal Akuntansi Dan Pajak, Vol. 17, no. 02,- 14. ISSN : 1412-629X

${ }^{13}$ Imam Ghozali, Imam Ghozali, Aplikasi Analisis Multivariate dengan Program SPSS, Cet . IV (Badan Penerbit Universitas Diponegoro, 2011), h 290 
honorer pada Taman Kanak-Kanak se Kecamatan Kendari Barat Kota Kendari Provinsi Sulawesi Tenggara. ${ }^{14}$

\section{Hasil dan Pembahasan}

Teknik pengolahan data dalam penelitian ini menggunakan teknik analisis Partial Least Square (PLS)dengan Program SmartPLS. Hasil analisis PLS dapat dilakukan dengan mengevaluasi model persamaan struktural. Dalam studi ini terdapat dua evaluasi mendasar dalam analisis PLS yaitu: Pertama, evaluasi model pengukuran (outer model) untuk mengetahui validitas dan reliabilitas indikator-indikator yang mengukur variabel laten; kriteria uji validitas dan reliabilitas instrumen pada penelitian ini mengacu pada discriminant validity, convergent validity, dan composite reliability. Keduamenilai inner model atau structural model untuk melihat hubungan antar konstruk, nilai signifikansi dan $R$-square dari model penelitian. Pengujian inner model dalam analisis PLS dilakukan melalui resampling bootstrap.

\section{Evaluasi Model Pengukuran (Outer Model)}

1. Convergent validity (Uji validitas)

Evaluasi Pengukuran Variabel Kompetensi Profesional Guru

\begin{tabular}{|l|l|}
\hline Indikator Variabel & $\begin{array}{l}\text { Outer } \\
\text { loading }\end{array}$ \\
\hline $\begin{array}{l}\mathrm{X}_{1} . \text { Mengerti dan dapat menerapkan landasan } \\
\text { kependidikan }\end{array}$ & 1.618473 \\
\hline $\begin{array}{l}\mathrm{X}_{2} \text {. Menerapkan teori belajar sesuai dengan taraf } \\
\text { perkembangan Anak }\end{array}$ & 3.021594 \\
\hline $\begin{array}{l}\mathrm{X}_{3} \text {. Mengembangkan bidang studi yang menjadi } \\
\text { tanggung jawab guru }\end{array}$ & 0.711505 \\
\hline $\begin{array}{l}\mathrm{X}_{4} \text {. Mengerti dan dapat menerapkan metode } \\
\text { pembelajaran yang berfariasi }\end{array}$ & 1.229393 \\
\hline $\begin{array}{l}\mathrm{X}_{5} \text { Mengembangkan dan menggunakan berbagai } \\
\text { alat media dan sumber belajar }\end{array}$ & 0.894104 \\
\hline $\begin{array}{l}\mathrm{X}_{6} . \text { Mampu mengorganisasikan dan melaksanakan } \\
\text { program pembelajaran }\end{array}$ & 0.933619 \\
\hline
\end{tabular}

${ }^{14}$ Moh.Kasiram. 2010.Metode Penelitian Kualitatif dan Kuantitatif, Cet.I Yogyakarta: UIN Maliki Press. h. 269 


\begin{tabular}{|l|l|}
$\mathbf{X}_{\text {7. }}$ Melaksanakan evaluasi hasil belajar & 3.104180 \\
\hline $\mathrm{X}_{8 .}$ Mampu menumbuhkan kepribadian siswa & 1.750030 \\
\hline $\mathrm{X}_{9 .}$ Memahami jenis-jenis materi pembelajaran & 0.744767 \\
\hline $\mathrm{X}_{10 .}$ Komunikatif dalam berbagai situasi & 0.757269 \\
\hline
\end{tabular}

Sumber : Hasil olahan data PLS, Tahun 2018

Evaluasi Pengukuran Variabel Motivasi Kerja

\begin{tabular}{|l|c|}
\hline \multicolumn{1}{|c|}{ Indikator Variabel } & Outer loading \\
\hline Y $_{\text {1.1. }}$ Prestasi & 3.125345 \\
\hline$Y_{1.2 .}$ Pengakuan & 2.126359 \\
\hline$Y_{1.3 .}$ Tanggung jawab & 1.570174 \\
\hline$Y_{1.4 .}$ Promosi & 2.475912 \\
\hline$Y_{1.5 .}$ Pertumbuhan & 2.671479 \\
\hline
\end{tabular}

2. Uji Average Variance Extracted AVE $>0,5$

\begin{tabular}{|c|c|}
\hline & AVE \\
\hline \hline Kompetensi Profesional Guru & 2.926487 \\
\hline Motivasi kerja & 6.004315 \\
\hline
\end{tabular}

olahan data PLS, Tahun 2018

Sumber : Hasil

Dari hasil uji AVE terlihat bahwa variabel kompetensi professional guru sebesar 2,926487 serta untuk variabel motivasi kerja sebesar 6,004315. Hal ini menunjukkan bahwa kedua variabel tersebut memiliki nilai AVE lebih besar dari 0,5. Sehingga dapat disimpulkan bahwa tidak ada masalah Convergent validity pada model yang diuji.

3. Uji Composite Reliability dan Cronbach's Alpha

\begin{tabular}{|c|c|}
\hline & Composite Reliability \\
\hline Kompetensi Profesional Guru & 1.096936 \\
\hline Motivasi kerja & 1.211614 \\
\hline
\end{tabular}


Hasil pengujian pada Tabel diperoleh nilai composite reliability variabel kompetensi profesional guru danmotivasi kerja menunjukkan bahwa kedua variabel laten yang dianalisis memiliki reliabilitas komposit yang baik karena nilainya lebih besar dari 0,70. Selanjutnya nilai cronbach's alpha dapat dilihat pada table dibawah ini.

\begin{tabular}{|c|c|}
\hline & Cronbachs Alpha \\
\hline Kompetensi Profesional Guru & 0.953476 \\
\hline \hline Motivasi kerja & 0.894983 \\
\hline
\end{tabular}

Dari hasil pengujian cronbach's alpha pada Tabeldiperoleh nilai cronbach's alpha variabel kompetensi profesional guru danmotivasi kerja menunjukkan bahwa kedua variabel laten yang dianalisis memiliki reliabilitas komposit yang baik karena nilainya lebih besar dari 0,70. Dapat disimpulkan bahwa seluruh instrumen yang digunakan dalam penelitian ini telah memenuhi kriteria atau layak untuk digunakan dalam pengukuran keseluruhan variabel laten yaknikompetensi profesional guru dan motivasi kerja karena memiliki kesesuaian dan keandalan yang tinggi.

\section{Discriminant Validity}

\begin{tabular}{|c|c|c|}
\hline \hline & $\sqrt{A V E}$ & AVt \\
\hline Kompetensi Profesional Guru & 2.926487 & 1.710698 \\
\hline \hline Motivasi kerja & 6.004315 & 2.450370 \\
\hline
\end{tabular}

Dari hasil pengujian seperti terlihat pada Tabel menunjukkan nilai square root of average variance extracted ( $\sqrt{\mathrm{AVE}}$ ) lebih besar dibandingkan dengan korelasi antara variabel laten dengan variabel laten lainnya, sehingga instrumen setiap variabel dikatakan valid diskriminan. Selain itu diperoleh nilai akar AVE variabel kompetensi profesional guru danmotivasi kerja lebih besar dari korelasi variabel laten bersangkutan dengan variabel laten lainnya dan masih di atas 0,70 (batas toleransi). Artinya konstruk variabel laten kompetensi profesional guru danmotivasi kerja memiliki discriminant validity yang baik. Dengan demikian instrumen penelitian yang digunakan untuk mengukur seluruh 
variabel laten atau konstruk dalam penelitian ini memenuhi kriteria validitas diskriminan.

\section{Evaluasi Model Struktural (inner model)}

1. Uji T Analisis Path

Berdasarkan hasil perhitungan uji-t untuk data kompetensi profesional guru dan Motivasi semua indikator diperoleh nilai $t_{h i t}>$ $t_{t a b}$ artinya semua indikator Kompetensi Profesional Guru dan morivasi memiliki nilai yang signifikan. Hal ini dapat dilihat pada gambar dibawah ini.

\section{R Square}

\begin{tabular}{|l|l|}
\hline & R Square \\
\hline Kompetensi Profesional Guru & \\
\hline Motivasi Kerja & 0.326567 \\
\hline
\end{tabular}

Pada table diatas diperoleh nilai $R$-square sebesar 0,327 .

Hasil ini menunjukkan bahwa sebesar $32,7 \%$ kompetensi professional guru dipengaruhi oleh motivasi kerja.

\section{Pengujian koefisien jalur}

Hasil pengujian pada Gambar diatas diperoleh bahwa kompetensi professional guru berpengaruh positif dan signifikan terhadap motivasi kerja. Hasil pengujian pengaruh antar variabel Gambar 3 secara lengkap dapat disajikan pada Tabel dibawah ini:

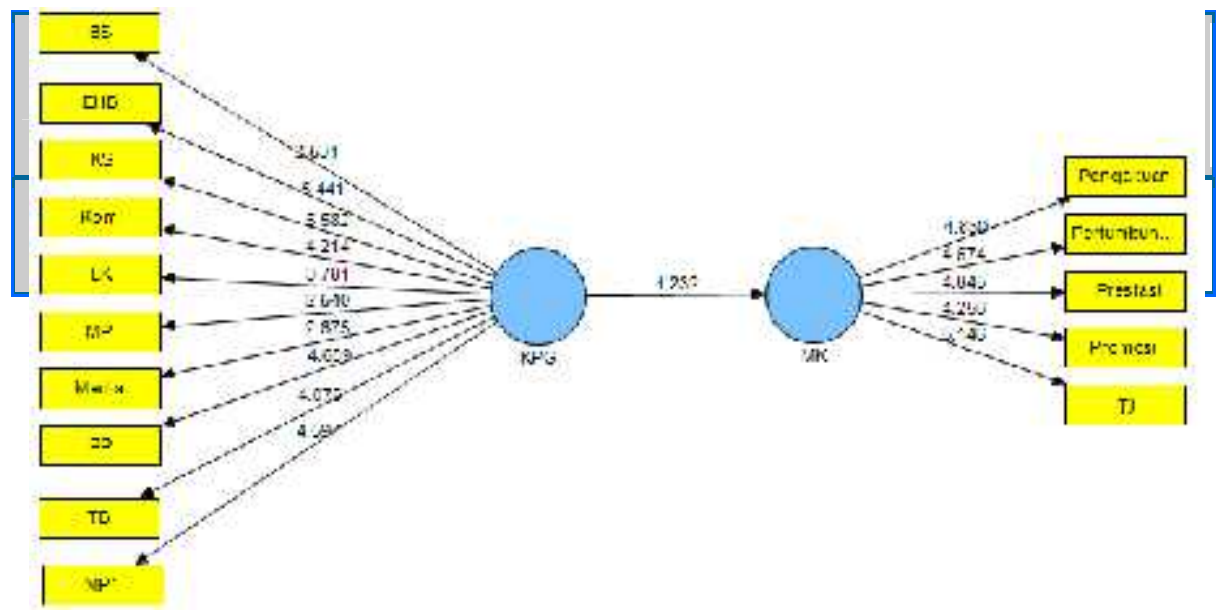

Keterangan : KPG = Kompetensi Profesional Guru; MK = Motivasi Kerja 


\begin{tabular}{|l|c|}
\hline & T Statistics (|O/STERR|) \\
\hline KPG -> MK & 4.231731 \\
\hline
\end{tabular}

T stat $>1,96$ : Berpengaruh

\section{Pengujian Hipotesis}

Darihasil pengujian hipotesis menunjukkan bahwa kompetensi professional guru berpengaruh secara signifikan terhadap motivasi kerja.Ini terlihat dari nilai koefisien jalur sebesar 0,571 dengan nilai t sebesar 4,232. Nilai tersebut lebih besar dari nilai t table 1,96. Hal ini berarti $\mathrm{H}_{0}$ ditolak sedangkan $\mathrm{H}_{1}$ diterima.

\section{Pembahasan}

Kompetensi profesional guru yang dimaksud dalam penelitian ini adalah tanggapan para guru tentang: penerapan landasan pendidikan, penerapan teori belajar, mengembangkan bidang studi, menerapkan metode pemelajaran, mengembangkan media pembelajaran, melaksanakan program pembelajaran, melaksanakan evaluasi hasil belajar, menumbuhkan kepribadian siswa, memahami materi pembelajaran, dan komunikatif.

Pentingnya mengkaji kompetensi profesional guru terhadap motivasi kerja didasarkan pada pendapat yang dikemukakan oleh Djamarah mengemukakan bahwa kompetensi profesional guru adalah penguasan sejumlah kompetensi sebagai keterampilan da keahlian yang diperlukan untuk melaksanakan tugas mendidik dan mengajar secara efektif dan efisien. ${ }^{15}$

Fakta dilapangan berdasarkan deskripsi variabel menunjukkan kondisi empiris implementasi kompetensi profesional guru yang difokuskan pada komunikatif jika dilihat dari penerapan landasan pendidikan, penerapan teori belajar, mengembangkan bidang studi, menerapkan metode pemelajaran, mengembangkan media pembelajaran, melaksanakan program pembelajaran, melaksanakan evaluasi hasil belajar, menumbuhkan kepribadian siswa, memahami materi pembelajaran sebagian responden menyatakan setuju atau sudah dilaksanakan dengan baik. Hasil penilaian responden terhadap kompetensi profesional guru, indikator melaksanakan evaluasi hasil belajar memiliki skor rata-

\footnotetext{
${ }^{15}$ Djamarah, Syaiful ahri. 2002. Strategi Belajar Mengajar. Jakarta : PT. Rineka Cipta., h. 65
} 
rata tertinggi. Namun berdasarkan pengujian nilai estimate loading indikator yang memiliki konstribusi dominan atau dipandang paling penting/kuat dalam merefleksikan kompetensi profesional guru adalah indikator melaksanakan evaluasi hasil belajar.

Variabel kompetensi profesional guru berdasarkan hasil pengujian lebih banyak direfeksikan oleh indikator melaksanakan evaluasi hasil belajar, namun fakta empiris belum dijadikan sebagai pertimbangan yang utama atau prioritasdalam penerapannya karena menurut penilaian responden yang didahulukan dalam pelaksanaannya yaitu indikator komunikatif.Artinya jika dilihat dari fakta empiris untuk meningkatkan kompetensi profesional guru adalah indikator komunikatif.

Pengujian model pengukuran nilai estimasi loading yangdipandang paling kuat/penting dalam merefleksikan kompetensi profesional guru yaitu indikator menumbuhkan evaluasi hasil belajar.Hasil pengujian model pengukuran dalam penelitian ini mampu membuktikan bahwa kesepuluh indikator adalah valid untuk digunakan dalam merefleksikan pengukuran variabel kompetensi profesional guru. Hasil ini mencerminkan bahwa korelasi di antara kesepuluh indikator variabel positif dan signifikan.

Hasil pengujian pengaruh kompetensi profesional guru terhadap Motivasi Kerja dapat dibuktikan dengan nilai estimate koefisien jalurmenunjukkanadanya pengaruh positif dan signifikan. Hasil pengujian membuktikan bahwa semakin baik kompetensi profesional guru, maka motivasi kerja semakin meningkat. artinya peningkatan kompetensi profesional guru searah dan nyata terhadap peningkatan motivasi kerja, dengan kata lain hasil penelitian ini mencerminkan bahwa kompetensi profesional guru yang baik mampu mendukung perubahan pada peningkatan motivasi kerja. Hal ini serupa dengan penelitian yang dilakukan oleh Astrid dan Tjutju pada seluruh guru di SMK Pasundan 3 Bandung, yang menemukan bahwa kompetensi profesional guru berpengaruh positif dan signifikan terhadap motivasi kerja setelah dianalisis dengan nilai koefesien determinasi yang diperoleh dalam penelitian ini adalah sebesar $18,34 \% .{ }^{16}$ Sejalan dengan hasil penelitian Maria

${ }^{16}$ Astrid Setianing Hartanti, Tjutju Yuniarsih. 2018. (The Effect Of The Professional Competence Of Teachers And Motivation Of Work On Teacher 
menemukan bahwa sebagian besar karyawan memiliki motivasi kerja rendah, dan sebagian besar karyawan memiliki kepuasan kerja pada kategori kurang puas.Karena itu kepala sekolah perlu memperhatikan berbagai faktor yang dimungkinkan berpengaruh terhadap kepuasan kerja guru, seperti kondisi organisasi sekolah, kondisi pekerjaan, gaji/insentif, supervisi kepala sekolah, hubungan guru dengan guru dan karyawan, serta promosi jabatan. ${ }^{17}$ Ini selaras dengan penelitian Ghenghesh seperti yang telah dipaparkan, bahwa motivasi dan kepuasan kerja adalah faktor penting yang mampu mempengaruhi produktivitas dan efektivitas organisasi. ${ }^{18}$

\section{Penutup}

Berdasarkan pengujian hipotesis dan hasil pembahasan maka dapat ditarik kesimpulan bahwa kompetensi profesional guru berpengaruh signifikan terhadap motivasi kerja. Hal ini dibuktikan dengan nilai estimate koefisien jalur sebesar 0,571 dengan nilai $t$ sebesar 4,232 dengan arah positif hal ini membuktikan bahwa semakin baik kompetensi profesional guru, maka motivasi kerja kerja semakin meningkat. Artinya peningkatan kompetensi profesional guru searah dan nyata terhadap motivasi kerja.

Performance In School High school). Jurnal Pendidikan Manajemen Perkantoran Vol.1_No.2_hal. 19-27

${ }^{17}$ Maria LUT, Dina. 2012. "Connection Between Job Motivation, Job Satisfaction and Work Performance in Romanian Trade Enterprises". Economics and Applied Informatics. Years XVIII-No.3.ISSN 1584-0409.page 45-50.

${ }^{18}$ Ghenghesh, Pauline. 2013. "Job Satisfaction and Motivation - What Makes Teachers Tick?'British Journal of Education, Society \& Behavioural Science.Vol. 3(4).page 456-466. 


\section{Daftar Pustaka}

Adnan Hakim. 2015. Contribution of Competence Teacher (Pedagogical, Personality, Professional Competence and Social) On the Performance of Learning. The International Journal Of Engineering And Science (IJES) Volume 4 Issue 2,3 .

Arikunto, Suharsimi. 2006. Prosedur Penelitian Suatu Pendekatan Praktik. Jakarta: Rineka Cipta

Ates, H., Yildiz, B., \& Yildiz, H. 2012. Can Herzberg's Two Factor Theory Explain the Motivation Perceptions of Teachers in Public Schools? An Empirical Research, Knowledge Economy and Management Magazine, VII(II), 147-162

Bambang Prasetyo dan Lina Miftahul Jannah. 2005. Metode penelitian kuantitatif (Teori dan Aplikasi). Jakarta: Raja Grafindo Persada.

Dwi Puji Lestari dan Budi Sutrisno. 2015. Pengaruh Profesionalisme Guru Dan Persepsi Guru Tentang Kepemimpinan Kepala Sekolah Terhadap Kinerja Guru Di Sma Sragen Kota . Artikel Publikasi. Universitas Muhammadiyah Surakarta. h.8

Endang Mulyaningsih. 2012. Metode Penelitian Terapan Bidang Pendidikan, Bandung:Alfabeta. h. 34-3

Eko Putro Widyoko. 2008. Analisis Pengaruh Kinerja Guru terhadap Motivasi Belajar Siswa .Penelitian tidak diterbitkan. h.3

Feralys Novauli, M. 2015. Kompetensi Guru dalam Meningkatkan Prestasi Belajar. Jurnal Administrasi Pendidikan Pascasarjana Universitas Syiah Kuala. Vol,3.

Ghenghesh, Pauline. 2013. "Job Satisfaction and Motivation - What Makes Teachers Tick?"British Journal of Education, Society \& Behavioural Science.Vol. 3(4).page 456-466.

Ghozali, Imam. 2011. Aplikasi Analisis Multivariate dengan Program SPSS, Cet .IV , (Badan Penerbit Universitas Diponegoro. h. 267

H. Muhammad Arifin. 2014. The Influence of Competence, Motivation, and Organisational Culture to High School Teacher Job Satisfaction and Performance. Canadian Center of Science and Education.

Haniatin Nabila. 2016. ISSN: 2528-617X. Yogyakarta. 
Hasibuan, Malayu S.P. 1986. Manajemen, Dasar, Pengertian dan Masalah, Jakarta : Gunung Agung. h. 344.

Jafaruddin.2015. Kompetensi Profesional Guru Dalam Meningkatkan Prestasi Belajar Siswa SMAN 1 Kuta Cot Glie Kabupaten Aceh Besar.Intelektualita Volume 1 No. 3, 63

JasonA.Colquitt.JefferyA.Lepine.MichaelJ.Wesson.2011.Organizatio nalBehavior.New York.McGraw-Hill Companies,Inc.

Karweti E. 2010. Influence managerial ability of principals and factors affecting the motivation work on the performance of special-ed teacher in the district Subang. [Journal] Educational Research. Vol. 11 No. 2

Kasmawati.2015. Pengaruh Guru Profesional Terhadap Motivasi Belajar Peserta Didik Pada SMPN 1 Bontoramba Kabupaten Jeneponto.Auladuna, vol. 2 no. 1 juni: 42-64

Kasmawati dan Masriani Adilla.2018. Pengaruh Kompetensi Manajerial dan Kompetensi Profesional.Jurnal Idaarah, Vol.2, No.1

Maria LUT, Dina. 2012. "Connection Between Job Motivation, Job Satisfaction and Work Performance in Romanian Trade Enterprises". Economics and Applied Informatics. Years XVIII-No.3.ISSN 1584-0409.page 45-50.

Maulinar. 2015. Kompetensi Guru Dalam Memotivasi Siswa Dalam proses Pembelajaran Pada SMP Negeri 1 Syamtalira Bayu Kabupaten Aceh Utara. Jurnal Administrasi Pendidikan Pascasarjana Unsiyah Vol 3 No 1, 142-157.

Moh.Kasiram. 2010.Metode Penelitian Kualitatif dan Kuantitatif, Cet.I Yogyakarta: UIN Maliki Press. h. 269

Mohamad Syarif Sumantri \& Prayuningtyas Angger Whardani. 2017. Relationship between Motivation to Achieve and Professional Competence in the Performance of Elementary School Teachers. International Education Studies; Vol. 10, No. 7; 2017 ISSN 1913-9020 E-ISSN 1913-9039.

Rika Anggela. 2015. Hubungan antara Kompetensi Profesional Guru dan Motivasi Kerja Guru dengan Prestasi Belajar. Jurnal Edukasi, Vol.13, No.1

Simamora. 2004. Manajemen Sumber Daya Manusia. Yogyakarta: UPPAMP YKPN, h. 333. 
Sofyan Yamin dan Heri Kurniawan. 2011. Generasi Baru Mengolah Data Penelitian Dengan Partial Least Square Path Modeling. Jakarta: Salemba Infotek.

Tecer, O. 2011. The Effect of Teachers' Internal Motivation Job Satisfaction Levels of School Supervisors Made by Primary Education Inspectors, Unpublished Master's Thesis, Ahi University Social Science

Titin Eka Ardiana. 2017. Pengaruh Motivasi Kerja Guru Terhadap Kinerja Guru Akuntansi Smk Di Kota Madiun.Jurnal Akuntansi Dan Pajak, Vol. 17, no. 02,- 14. ISSN : 1412$629 \mathrm{X}$

Yavuz, C., \& Karadeniz, C. B. 2009.The Effect of Classroom Teacher Motivation on Job Satisfaction, International Social Research Journal, 2, 9.

Zamharil Yahya dan Fitri Hidayati. 2017. Analisis Kompetensi Terhadap Penilaian Kinerja Dosen (Studi Kasus Dosen UIN Sultan Syarif Kasim Riau). Jurnal Penelitian sosial keagamaan, Vol.17, No.1

Zimnyaya, I. A. 2004. Key competencies as effectively targeted basis of competence approach in education. Author's version. Moscow: Research center of quality problems of specialists training. 